\title{
PERUBAHAN DAN INOVASI MEDIA RADIO DI ERA DIGITAL
}

\author{
Mohammad Ismed \\ Program Studi Penyiaran, Jurusan Penerbitan, Politeknik Negeri Media Kreatif \\ Korespondensi: Jalan Srengseng Sawah, Jagakarsa, Jakarta Selatan \\ Surel: ismednompo@gmail.com
}

\section{INFO ARTIKEL}

\section{Sejarah Artikel:}

Diterima: 25/02/20

Direvisi: 27/04/20

Dipublikasikan: 31/05/20

e-ISSN: 2721-0995

p-ISSN: 2721-9046

\section{Kata Kunci:}

Inovasi, Media Radio, Konvergensi Media, Tri-O

\section{Keywords:}

Innovation, Radio Media, Media Convergence, Tri-O

\begin{abstract}
ABSTRAK
Perubahan dan Inovasi Media Radio di Era Digital. Penelitian ini bertujuan menganalisis perubahan yang dilakukan radio dalam menghadapi era digital, yakni perubahan customer media radio dibandingkan sebelumnya serta perubahan bisnis dan inovasi agar bisa tetap bertahan dan eksis di era digital. Dengan pendekatan kualitatif, metode interview dan observasi digunakan secara deskriptif. Hasil penelitian ini menyimpulkan bahwa perkembangan teknologi digital telah mengubah cara pendengar dalam mendengarkan radio. Begitu juga dengan gaya hidup dan saluran yang digunakannya. Karena itulah radio harus ikut berubah dengan beradaptasi, baik dari model bisnisnya maupun cara menyampaikan program kepada pendengarnya. Untuk itu radio melakukan inovasi dengan apa yang disebut dengan Tri-O, yaitu pengintegrasian konsep penyajian program dan penempatan iklan dari segi On Air, Off Air, dan Online sebagai hasil proses evolusi yang dijalankan oleh radio itu sendiri. Dengan segala hasil inovasi yang dilakukan media radio, memunculkan kenyataan bahwa radio bukan lagi hanya berupa audio, tetapi dapat juga ditambah dengan aspek visual.
\end{abstract}

\begin{abstract}
A B STRACT
The Changes and Innovation of Radio Media in the Digital Era. This study aims at analyzing the changes made by radio in the digital era in radio's customers compared to what happened in the past. Both changes in business and radio innovation are also discussed. With qualitative approach and descriptive interview and observation methods, this study concluded that the development of digital technology has changed the way of listeners towards the radio. Additionally. the lifestyle and the channels' usages also changed. For this reason, radio innovates with what is called Tri-O, the integration of the concept of program presentation and ad placement in terms of On Air, Off Air and also Online as a result of the evolutionary process carried out by the radio itself. With all the innovations made by radio media, the fact that radio is no longer just audio can also be added to the visual aspect.
\end{abstract}




\section{MEDIASI Vol. 1 No. 2, Mei 2020}

Mohammad Ismed

\section{PENDAHULUAN}

Radio adalah media massa yang memiliki sejarah panjang dan tumbuh dari teknologi sebelumnya, seperti telepon, telegraf, dan perekaman suara. Dari bentuk penyiaran tunggal, penyiaran radio mengalami perubahan bentuk yang berbeda, yakni para pemilik radio swasta yang tergabung dalam suatu jaringan, kemudian menentukan sebagian besar program pilihan yang didukung oleh iklan komersial. Inilah bentuk model yang masih bertahan hingga saat ini. Dengan adanya teknologi FM, radio pun lalu berkembang dengan memberikan kualitas yang lebih baik dari suara dan juga secara teknis mampu menjangkau lebih banyak lagi khalayak. Bentuk ini menyebabkan kompetisi semakin tajam dalam dunia radio itu sendiri.

Hadirnya televisi membuat spekulasi bahwa radio akan ditinggalkan dan konsumen akan beralih ke televisi yang notabene lebih memiliki keunggulan, yakni tidak hanya menghasilkan suara tetapi juga gambar bergerak yang memberikan arti baru bagi dunia hiburan. Uniknya, dengan kemunculan televisi tersebut ternyata radio tidak juga hilang dari dunia. Radio menemukan cara, alih-alih berkompetisi dengan televisi, radio melakukan inovasi dengan memberikan pengalaman langsung kepada para pendengarnya untuk dapat berinteraksi dan bertemu langsung dengan broadcaster yang biasanya hanya terdengar suaranya dalam membawakan program radio. Hal ini disebut sebagai kegiatan off-air, yakni acara langsung yang dilakukan di luar studio siaran.

Tidak berhenti hingga munculnya televisi saja. Teknologi media telah berkembang dengan sangat cepat dan berubah di setiap generasi. Radio yang kini merupakan salah satu media lama ikut berkembang dengan hadirnya media baru dengan teknologi digital. Penyiaran radio masih menggunakan medium analog. Mereka masih menggunakan pemancar analog tetapi telah memutarkan musik yang sudah disimpan dalam perekaman digital. Hal ini menunjukkan bahwa media lama telah merespon inovasi digital dengan caranya sendiri.

Tidak sedikit yang mengatakan bahwa era radio akan segera berakhir di era digital ini yang ditandai dengan penurunan pendapatan iklan serta pendengarnya yang beralih ke media baru. Bagi para praktisi yang lama menggeluti dunia penyiaran radio merasa bahwa radio tidak akan mati namun berkembang dan dapat menyesuaikan dengan zaman. Penyesuaian ini tidak menghilangkan esensi dari radio itu sendiri, justru mendukung radio untuk menjalani karakteristik sebagai salah satu media massa yang akan tetap menjadi pilihan.

Salah satu alasan untuk mendengarkan radio adalah untuk mendengarkan lagu. Oleh karena itu, lagu merupakan suatu hal penting dari bagian konten siaran radio. Meskipun teknologi digital juga telah mengembangkan platform baru untuk mendengarkan musik, seperti ITunes, Spotify atau situs-situs streaming lainnya. Namun, konsumen yang dalam hal ini adalah pendengar masih loyal mendengarkan radio. Alasannya adalah bahwa radio mempunyai peran yang jelas sebagai hiburan berbasis audio. Selain musik, program dan juga penyiar yang membawakannya masih menjadi faktor yang memikat orang untuk 
mendengarkan radio. Kedua hal itulah yang tidak bisa disediakan oleh situs-situs streaming musik. Seperti yang dipaparkan dalam survei Nielsen Radio Consumer View berikut ini.

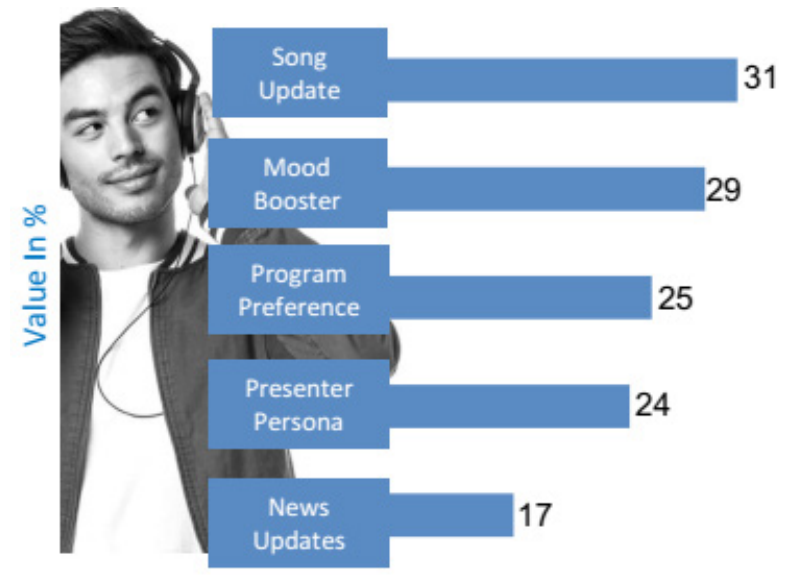

Sumber:Nielsen RCV Q2 2017. Total individu 10t. 11 kota

Gambar 1. Survei tentang peran radio bagi pendengar.

Dari hasil survei Nielsen tersebut, bisa disimpulkan bahwa radio merupakan onestop hiburan dalam format yang menjadikan konsumen dapat menikmati tidak hanya musik, tetapi juga program special (talk show, ceramah religi atau dialog tradisional, yang cukup dinikmati oleh pendengar di Indonesia). Selain itu, presenter juga menjadi fakta yang meyakinkan bahwa pendengar masih cenderung mengandalkan program yang interaktif dan mengikutsertakan pendengar dibandingkan dengan musik nonstop tanpa diselingi informasi ataupun humor khas para presenter. Intinya adalah bahwa stasiun radio menawarkan nilai lebih dengan program-program spesial dan presenter sehingga radio bisa menjaga pendengarnya dan juga eksitensinya.

Kemunculan radio online yang merupakan konvergensi radio konvensional dan digital, membuat radio tetap dapat dinikmati dengan teknologi saat ini. Tanpa menghilangkan kekhasan radio, yakni 'dekat', radio online tetap memiliki tempat sebagai sebuah lembaga bisnis. Khususnya bagi radio yang memiliki jaringan dan juga memiliki radio siaran konvensional, membuat radio tetap menjadi salah satu media massa yang belum dan mungkin tidak tergantikan. Bahkan, Program Director Woman Radio, Dr. Lia Hafiz menyatakan bahwa karakteristik radio yang sudah ada, seperti interaktif, personal, akrab dan lainnya sebenarnya merupakan cikal bakal dari media baru (digital) yang muncul sekarang ini. Jadi, sepanjang sejarahnya terlihat bahwa radio mampu menyesuaikan diri, berkembang ataupun melakukan evolusi dan inovasi untuk eksis sebagai sebuah media massa yang memiliki entitas bisnis di dalamnya karena mempunyai dasar karakteristik tersebut. Dari penjabaran tersebut bisa dikatakan bahwa radio dapat bertahan. Bagaimana radio dapat bertahan dan perubahan serta inovasi seperti apa yang memberikan kekuatan 
bagi radio untuk terus berjaya di udara merupakan hal yang menarik untuk diteliti. Hal ini diperkuat dengan preliminary data yang didapat bahwa radio melakukan perubahan serta inovasi dengan menggabungkan konsep-konsep program dengan marketing dan promosi yang lebih berorientasi pada pendengar.

\section{TINJAUAN PUSTAKA}

Penelitian ini didasari berbagai teori dalam menyusun konsep permasalahan yang dibahas. Teori tersebut terdiri atas berbagai teori mengenai media massa, radio dan juga difusi inovasi dan juga ekologi media. Teori komunikasi massa yang digunakan adalah mengenai Media Massa (Fauziahardiyani, 2009), Penyiaran Radio (Cangara, 2002) dan (Nurudin, 2007). Dalam penelitian ini tidak luput disampaikan dasar UU Penyiaran Nomor 22 Tahun 2000 mengenai Media Massa dan Radio. Adapun teori radio yang digunakan adalah teori yang dikemukakan oleh Masduki (1996:15). Radio adalah media auditif, murah, merakyat, dan bisa dibawa serta didengar di mana saja (Wahyudi, 1994: 16). Masih mengenai radio, karakteristik media dan radio yang disampaikan oleh Frank Jefkins (1996:101), Schupan yang dikutip kembali oleh Niken Widiastuti (1992:3) dan juga Soemarjan (1990:189) serta teori lainnya dari Dennis McQuail (2002) Burhan Bugin (2005). Dalam kaitannya dengan bisnis radio, dasar bisnis radio, yakni rating (Straubhaar, LaRose, Davenport, 2010:169) juga dijabarkan pada penelitian ini. Selain itu, konsep pemikiran terkait radio yang tertuang dalam Media Now (2010:169), Straubhaar (Steve Warren, Radio: The Book, 2005:170), juga mempertajam pembahasan mengenai radio itu sendiri.

Selain media massa dan radio, secara spesifik penulis mendasarkan penelitian dan pembahasan pada teori Difusi Inovasi yang dikemukakan oleh Everette M. Rogers. Difusi Inovasi didefinisikan sebagai proses dari suatu inovasi yang dikomunikasikan melalui saluran tertentu dalam jangka waktu tertentu di antara para anggota suatu sistem sosial. Hal yang memengaruhi hal ini adalah Inovasi, Saluran Komunikasi, Waktu, dan Sistem Sosial. Dari kelima faktor tersebut, dapat disimpulkan bahwa semakin besar Relative Advantage; Compatibility, Trialability dan Observability serta semakin kecil Complexity, maka semakin cepat kemungkinan inovasi tersebut dapat diadopsi.

Teori Ekologi Media berpusat pada prinsip-prinsip bahwa masyarakat tidak bisa lepas dari pengaruh teknologi dan teknologi itu akan tetap menjadi sentral di hampir semua lapisan masyarakat (West, Richard; Turner, Lynn H., 2009:429). Konsep dasar teori ini pertama kali dikemukakan oleh Marshall McLuhan pada tahun 1964. McLuhan terkenal dengan kalimatnya,

"Medium adalah Pesan" (Medium is the Message) yang merupakan frasa yang sering diperdebatkan dan diyakini bahwa media yang dipilih untuk menyampaikan pesan adalah sama pentingnya (jika tidak lebih) dari pesan itu sendiri (McLuhan: 1964).

Penelitian tentang perubahan dan inovasi pada media radio belum pernah dilakukan 
oleh para peneliti atau akademisi. Bahkan, penelitian mengenai media radio pun tidak begitu banyak dilakukan. Tetapi ada beberapa hasil penelitian yang relevan untuk dijadikan bahan rujukan. Jurnal Ido Prijana Hadi, Vol 1, No 3, Juli 2011 di Program Studi IImu Komunikasi, Universitas Kristen Petra Surabaya yang berjudul "Pengguna Media Interaktif Sebagai Kenyataan Maya: Studi Resepsi Khalayak Suarasurabaya.net sebagai Media Interaktif", menjelaskan bahwa di tengah perkembangan dunia yang berubah dengan cepat, media di Indonesia juga mangalami transformasi dengan cepat. Selain itu, terdapat Jurnal Aprilani, Vol 1, No 2, Januari 2011 di Program Studi Ilmu Komunikasi STAIN Kediri yang berjudul "Radio Internet dalam Perspektif Determinisme Teknologi" menjelaskan bahwa penggabungan radio analog yang diseminatif dengan internet secara dialogis bukan lagi hal yang mustahil. Salah satu jurnal lainnya yang membahas mengenai radio adalah Laporan Musonomics, Larry S Miller, Steinhardt Music Business Program di New York University yang berjudul "Paradigm Shift: Why Radio Must Adapt to the Rise of Digital".

Berbagai landasan di atas memusatkan konsep yang terdapat di dalam penelitian ini pada perubahan dan inovasi itu sendiri serta cara penerapannya sebagai rencana strategis bisnis dalam mengantisipasi kompetisi yang semakin ketat dan tanpa akhir. Menurut J.S. Badudu dan Sutan Mohammad Zain, penerapan adalah hal, cara atau hasil (Badudu \& Zain, 1996:1487). Adapun menurut Lukman Ali, penerapan adalah mempraktikkan, memasangkan (Ali, 1995:1044). Berdasarkan pengertian tersebut dapat disimpulkan bahwa penerapan merupakan sebuah tindakan yang dilakukan baik secara individu maupun kelompok dengan maksud untuk mencapai tujuan yang telah dirumuskan.

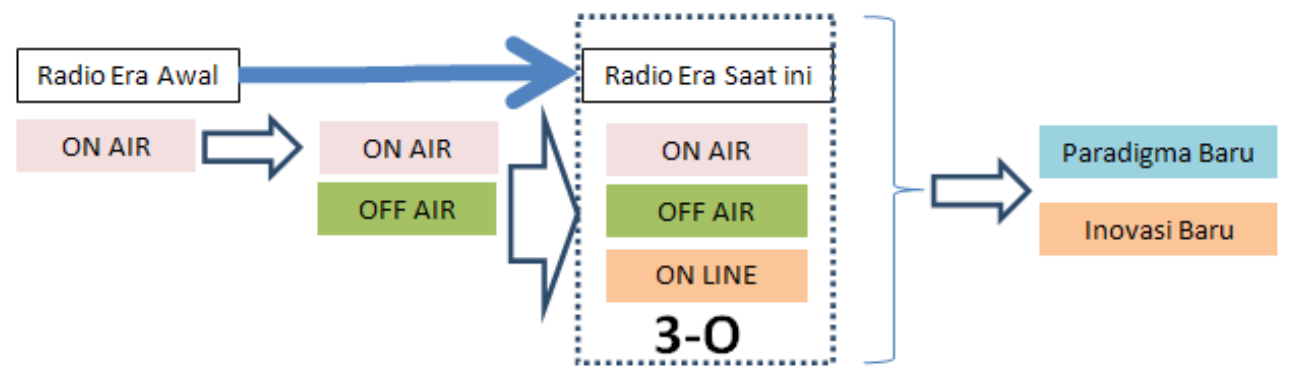

Gambar 1. Model Perkembangan Radio

Dari bagan di atas terlihat terjadinya transformasi atau perubahan pada bisnis model dari media radio yang mau tidak mau harus dilakukan karena terjadi juga perubahan pada audience yang terjadi terus menerus. Dengan inovasi yang terus menerus dilakukan, media radio akhirnya melakukan evolusi hingga akhirnya menemukan paradigma dan inovasi baru untuk bertahan dalam mengikuti perkembangan jaman. Dari bagan yang tersusun tersebut maka konsep pembahasan penelitian adalah seperti alur berikut ini. 


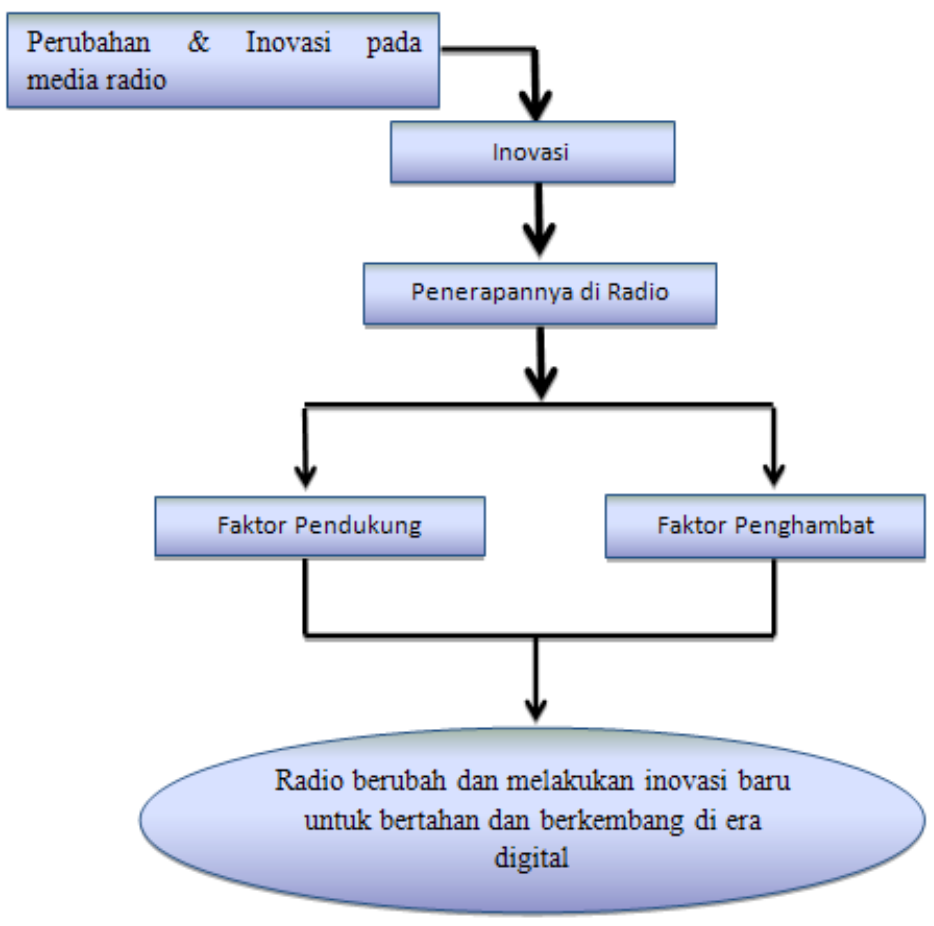

Gambar 3. Kerangka Penelitian

\section{METODE}

Penelitian ini menggunakan pendekatan kualitatif, yakni suatu pendekatan yang cenderung lebih mementingkan pada proses dibandingkan dengan hasil akhir. Oleh karena itu, urutan-urutan kegiatan dapat berubah-ubah tergantung pada kondisi dan banyaknya gejala-gejala yang ditemukan. Penelitian kualitatif biasanya menggunakan pendekatan induktif terhadap data penelitiannya. Hal ini berarti penelitian kualitatif tidak bermaksud untuk menguji sebuah hipotesis tetapi hanya mendeskripsikan, menggambarkan suatu kejadian (Daymond dan Holloway, 2011:107). Data penelitian kualitatif meliputi dokumentasi peristiwa nyata, merekam apa yang orang katakan (dengan kata, sikap dan nada), mengamati perilaku tertentu, mempelajari dokumen tertulis, atau memeriksa gambar visual (Neuman, 2014: 195).

Untuk mendukung penelitian ini menggunakan metode deskriptif yang menyajikan gambaran tentang rincian situasi yang spesifik, keadaan sosial, atau hubungannya (Neuman, 2014: 38). Kebanyakan penelitian sosial yang ditemukan di jurnal ilmiah atau yang digunakan untuk membuat keputusan kebijakan bersifat deskriptif. Penelitian deskriptif ini dapat menggambarkan, meringkas berbagai kondisi, situasi, atau berbagai fenomena realitas sosial yang ada di masyarakat yang menjadi objek penelitian, dan berupaya menarik realitas itu ke permukaan sebagai suatu ciri, karakter, sifat, model, tanda, atau gambaran, tentang kondisi, situasi, atau fenomena tertentu. 
Dalam penelitian ini, teknik penentuan informan dengan purposive sampling, yaitu sampel nonrandom yang artinya peneliti menggunakan berbagai metode untuk menemukan semua kemungkinan kasus populasi yang sangat spesifik dan sulit dijangkau (Neuman, 2014: 273).Penulis dalam penelitian ini menggunakan teknik analisis Coding \& Categorizing (Daymon and Holloway, 2011: 306-318). Langkah-langkah yang dilakukan adalah sebagai berikut:

1. Transcribing and listening merupakan proses mendengarkan dan pembuatan transkrip dari wawancara yang telah kita lakukan kepada narasumber. Setelah melakukan interview, hasilnya harus langsung didengarkan kembali dan dibuatkan transkrip. Hasil dari wawancara itu akan berupa data tertulis yang akan mempermudah dalam pengorganisasian dan dapat diverifikasi untuk dijadikan temuan penelitian terhadap masalah yang diteliti.

2. Organizing the data merupakan proses memeriksa semua hasil rekaman telah dicatat dan diberi label secara sistematis. Hal ini membantu dalam menjaga data agar tetap utuh, lengkap, teratur, dan dapat digunakan kembali. Periksa kualitas semua bukti yang telah dikumpulkan sebelum mulai menganalisis.

3. Coding and categorizing merupakan proses utama yang penting dalam analisis kualitatif yakni kita membuat pilihan mengenai kata-kata yang akan digunakan untuk memberi label gagasan atau tema yang dilihat berulang kali dalam data kita. Kode berfungsi sebagai label yang mewakili gagasan atau fenomena pada bagian sebuah teks yang serupa atau memiliki kesamaan arti. Kode membantu dalam mengurangi dan menyederhanakan bukti yang layak agar bisa mulai untuk memahaminya. Lakukan pengodean sepanjang analisis data.

4. Interpreting the data merupakan proses analisis untuk memberi makna pada data, menjelaskan kepada orang lain seperti pembaca, serta maksud dari data yang ada untuk membantu memahami apa yang telah kita temukan dalam penelitian.

5. Evaluating your interpretation merupakan proses pemaknaan yakni analisis kualitatif harus bermakna, berguna, dan kredibel. Jika kesimpulan yang didapat berkaitan langsung dengan pertanyaan yang diajukan, analisisnya akan bermakna. Jika interpretasi data dapat dipahami oleh pembaca dan disajikan dengan jelas, analisisnya berguna. Yang terakhir, untuk menjadi kredibel, kita harus menunjukkan bahwa perspektif yang disajikan akan sesuai dengan penelitian yang ketat, dengan mengacu pada kriteria kualitas tertentu, seperti reliabilitas dan validitas atau keaslian dan segala hal yang dipercaya lainnya.

\section{HASIL DAN PEMBAHASAN}

Hasil penelitian ini menjabarkan penemuan peneliti atas jawaban penelitian mengenai hal-hal yang mengarah pada tindakan yang dilakukan oleh media radio dalam menghadapi era digital seperti sekarang ini. Bagaimana langkah-langkah dan inovasi yang dilakukan agar bisa survive dan terus menjalani fungsinya sebagai sebuah media komunikasi massa di era digital. 
Berdasarkan hasil survei, responden menyatakan bahwa yang dilakukan media radio dalam menghadapi era digital adalah dengan ikut masuk dalam perkembangan teknologi digital. Selain itu, terdapat perbedaan pendengar radio dulu dan sekarang. Di era digital ini pendengar radio menjadi sangat visual oriented. Akan tetapi tidak membuat karakteristik radio menjadi hilang, justru semakin diperkuat dengan keluasan jangkauan dari teknologi digital itu sendiri.

Tantangan media radio saat ini terkait dengan perkembangan era digital yang telah membuat banyak perubahan, termasuk perubahan pada gaya hidup dan gaya masyarakat dalam mengonsumsi media. Selain itu, terdapat tantangan yang harus dihadapi oleh media radio di era digital ini adalah media-media digital yang ikut mempersempit jatah-jatah kue iklan yang tadinya adalah milik radio.

Perubahan bisnis media radio pun terjadi karena perubahan yang terjadi pada gaya hidup pendengar yang terpicu dari perkembangan teknologi digital. Media radio pun melakukan perubahan pada bisnisnya. Seperti responden 2 yang mengungkapkan bahwa pendengar dulu mendengarkan radio di mobil, tetapi sekarang sudah bergeser ke streaming. Mau tidak mau penyasaran pendengar diarahkan pada pengguna ponsel. Perubahan ini juga menjelaskan perubahan dari radio itu sendiri yang menabrak salah satu kaidah radio, yaitu theatre of mind. Hal itu dikarenakan radio saat ini juga menampilkan visual. Intinya, bisnis radio saat ini 'evolve'.

Perubahan yang terjadi dan pengaruhnya terhadap eksistensi radio dengan pergeseran yang terjadi pada pendengar sudah sangat visual. Mereka sudah bisa mencari lebih jauh mengenai informasi yang didapat dari media radio dengan difasilitasi oleh teknologi digital. Eksistensi radio kini disebut sebagai I 3-O. (I Tri-O)

Bentuk strategi bertahan yang diterapkan media radio pada dasarnya adalah sebuah adaptasi yang dilakukan oleh radio. Contohnya yang pertama radio menggunakan media sosial dan yang kedua adalah dengan menggunakan website yang kemudian diikuti dengan streaming. Inilah penjelasan konsep O pada awalnya adalah on air, lalu off air dan online. Bisa jadi akan ada $O$ lainnya sebagai cerminan adaptasi radio.

Inovasi yang dilakukan media radio agar tetap eksis. Adaptasi yang dilakukan diikuti pula oleh inovasi. Salah satu cara yang disampaikan adalah pentingnya dan perlunya radio masuk ke channel lainnya. Namun, hal-hal yang dilakukan oleh radio sebenarnya kembali kepada konten atau isi dari program yang diberikan. Dalam hal ini pelaku bisnis radio merupakan salah satu yang terkuat dalam menyusun konten.

Yang dilakukan radio untuk mempertahankan pendengar secara konkret terkait adaptasi dan inovasi adalah teknologi. Radio adalah persoalan pendengar. Apabila pendengar berubah mengikuti zaman, maka radio pun turut mengikuti. Teknologi mengenable radio untuk menggunakan visual. Hal ini terkait dengan karakteristik pendengar itu sendiri. Sebagai media, fungsi komunikasi dari radio tetap diutamakan dalam berhubungan dengan para pendengarnya. Dalam komunikasi massa yang dilakukan ini, radio juga memperkuat diri dengan memperluas jaringannya untuk memberikan komunikasi kepada 
massa lebih dari komunikasi kepada personal. Hal ini juga sebagai salah satu cara untuk meraih pendengar yang lebih banyak.

Perubahan bentuk radio tidak mengubah karakter radio itu sendiri.

"Kenapa orang ini ama radio, karena mereka itu ada sesuatu yang personal. Sesuatu yang memang cuma dia dan radio itu. Teman buat mereka... iya kan. Ada informasi bisa didapat. Hiburan bisa didapat. Semua tetap konsep seperti itu. Konsep radio tidak berubah, yang berubah adalah medianya. Tinggal dikembangkan aja."

Radio merupakan sesuatu yang ajaib.

"Karena radio itu adalah sesuatu yang ajaib, media yang ajaib menurut gw karena gw sampai sekarang suka di radio ya. Karena dari apapun media baru yg ada pada saat itu pada saat radio itu mengadaptasikan itu ke radio, radio itu tidak kehilangan karakteristiknya gitu, interaktivitasnya tetep ada. Menyajikan programnya sendiri juga tetep bisa, bahkan tidak hanya audionya saja tapi juga secara visual. Itu juga tetep ada, dan itu apakah menjadi sesuatu yg baru buat radio, ngga juga. Kalau kita lihat kan itu beda soalnya, kalau radio itu media massa, kalau yang satu lagi media personal. Tapi itu menurut gw sih ngga saling mematikan sih ya tapi itu dimanfaatkan untuk memang memperkuat posisi radio aja."

Menjabarkan media radio di masa depan, seluruh responden memiliki padangan yang positif untuk masa depan radio. Responden 1 menyatakan bahwa radio tidak akan mati, terutama yang tidak akan hilang adalah sifat dari radio itu sendiri yang menjadikan radio berbeda dengan media lain. Walaupun bentuk fisik radio tidaklah sama dengan yang saat ini kita ketahui, pada hakikatnya radio tetap akan hidup dengan bentuk yang berbeda.

\section{SIMPULAN}

Perubahan zaman yang dipicu oleh perkembangan teknologi merupakan tantangan pada setiap bisnis yang lebih dulu hadir sebelum era teknologi. Bahkan berbagai bisnis telah melakukan revolusi, bukan lagi evolusi pada bisnisnya demi bertahan. Akan tetapi, radio ternyata memiliki ketahanan lebih tinggi karena evolusi radio untuk bertahan dalam industri bisnis telah dilakukan jauh lebih lama sebelum era digital dimulai. Sifat radio seperti 'kecoak' karena memiliki sensitivitas yang tinggi untuk tahu kapan harus berubah dan beradaptasi.

Teknologi justru menguatkan karakteristik radio sebagai media yang dekat dengan pendengar. Radio yang dapat bertahan saat ini adalah radio yang menyadari hal ini dan melakukan inovasi yang searah dengan perkembangan teknologi.

Jadi kesimpulannya sebagai berikut:

1. Perubahan radio yang terjadi saat ini disebut sebagai Tri-O yakni On Air, Off Air, dan On line. Tri-O ini juga menandai perubahan proses bisnis radio. Hal inilah yang dilakukan radio sebagai inovasi untuk bertahan. Melalui Tri-O ini, selain inovasi juga menjelaskan evolusi radio itu sendiri. 
2. Perubahan radio dengan perjalanannya dengan Tri-O diinisiasi oleh teknologi yang dijalankan secara terpadu.

3. Perubahan yang terjadi dalam masyarakat turut mengubah perilaku konsumen dalam menikmati radio yang juga membuat radio beradaptasi untuk tetap mendapatkan konsumen.

4. Tantangan radio adalah perubahan teknologi itu sendiri, khususnya dalam memberikan 'teknologi' yang sesuai dengan perkembangan teknologi.

5. Bisnis radio berubah walaupun sebagian besar karakteristik radio tetap sama. Radio tetap akan hadir menemani masyarakat tetapi dengan bentuk yang berbeda dan secara unik diperkuat dengan perkembangan teknologi itu sendiri.

\section{DAFTAR RUJUKAN}

Aprilani (2011). Radio Internet dalam Perspektif Determinisme Teknologi. Jurnal Komunikasi. Vol.1(2), 159-170.

Ardianto, Elvinaro et al (2017). Komunikasi Massa - Suatu Pengantar Edisi Revisi. Bandung: Simbiosa Rekatama Media.

Baxter, Leslie A and Babbie, Earl (2004). The Basics of Communication Research. Wadsworth - Thomson Learning, USA

Campbell, Lewis and Garnett, William (1997). The Life of James Clerk Maxwell. London: Macmillan and Co.

Cangara, Hafied (2006). Pengantar Ilmu Komunikasi. Jakarta: PT. Raja Grafindo.

Daymon, Christine and Holloway, Immy. (2011). Qualitative Research Methods in Public Relations and Marketing Communications. $2^{\text {nd }}$ Ed. New York: Routledge.

Fauziahardiyani. (2009). Komunikasi dan Media Massa. Bandung: PT Remaja Rosdakarya. Ido Prijana (2011). Pengguna Media Interaktif Sebagai Kenyataan Maya: Studi Resepsi Khalayak Suarasurabaya.net Sebagai Media Interaktif. Jurnal ASPIKOM. Vol. 1(3), 231-244

Kotler, Philip; Kartajaya, Hermawan; Setiawan, Iwan. (2010). Marketing 3.0: From Products to Customer to The Human Spirit. New Jersey: John Wiley \& Sons Inc.

Kotler, Philip and Kartajaya, Hermawan (2010). Marketing 3.0: Values-Driven Marketing. Kellog School of Management. Jakarta: MarkPlus Inc.

Kurnia, Eddy (2013), Customer is Change: Eksplorasi Perilaku Pelanggan di Tengah Gaya Hidup Digital. Jakarta: Buku Republika.

Lawrence, Ben. (2017 February, 17). People say radio is dead. Actually, radio as content is exploding http://musically.com/2017/02/23/radio-dead-content-exploding/ diakses pada 8 Oktober 2017 pukul 23.36 WIB.

Mayo, Charles M. (2017). Integrated Marketing Communication. http://www.referenceforbusiness.com/management/Log-Mar/Marketing Communication.html. diakses pada 6 Agustus 2017, pukul 06.47 WIB.

McQuail, Dennis (2010), McQuail's Mass Communication Theory, $6^{\text {th }}$ Ed. London: Sage Publication.

McCurdy, Bob (2017, July 4). Radio is Not Dead. Here's Why. https://radioink.com/2017/07/04/true-grit/ diakses pada 8 Oktober 2017 pukul 23.33 WIB.

McIntyre, Hugh. (2015 Agust, 13) No, Radio Isn't Dead - In Fact, It's Doing Better Than Ever. https://www.forbes.com/sites/hughmcintyre/2015/08/13/no-radio-isnt-dead-in- 
fact-its-doing-better-than-ever/\#3a38508d4b59. diakses pada 8 Oktober 2017, pukul 23.30 WIB.

Miller, Larry S (2017). Paradigm Shift: Why Radio Must Adapt to the Rise of Digital.

Musonomics Reports. Steinhardt Music Business Program. New York: New York University.

Neuman, W. Lawrence. (2014). Social Research Methods: Qualitative and Quantitative Approaches, $7^{\text {th }}$ Ed. England: Pearson Education Limited.

Nurudin, M.Si. (2007). Pengantar Komunikasi Massa. Jakarta: PT Raja Grafindo Persada.

Pathak, Shareen (2014 September, 18). Why radio is not dead, in 5 charts. https://digiday. com/marketing/radio-not-dead/ diakses pada 7 Oktober 2017 pukul 13.50 WIB.

Rogers, Everett, M. (2003). Diffusions of Innovations; $5^{\text {th }}$ Ed. New York: Simon \& Schuster Publisher.

Romli, Asep Syamsul (2009). Dasar-Dasar Siaran Radio. Bandung: Nuansa Cendekia.

Schultz, Don E, Schultz, Heidi (2004). IMC - The Next Generation: Five Steps for Delivering Value and Measuring Financial Return. New York: McGraw-Hill

Schultz, Don E. (2010). New, Newer, Newest: Evolving Stages of IMC. Journal of Integrated Marketing Communications. JIMC 2010, 14-21

Senne, Matt (2017 May, 10). Is Radio Dead in 2017? http://blog.leightonbroadcasting.com/ blog/is-radio-dead-in-2017 diakses pada 8 Oktober 2017 pukul 23.39 WIB.

Straubhaar, Joseph, LaRose, Robert, and Davenport, Lucinda (2010). Media Now:

Understanding Media, Culture and Technology; $7^{\text {th }}$ Ed. Boston: Cengage Learning.

Turner, West. (2007). Introducing Communication Theory (Analysis and Application) $3^{\text {rd }}$ Ed. New York: McGraw Hill. 